\title{
Sentidos e significados da participação democrática através da Internet: uma análise da experiência do Orçamento Participativo Digital
}

\author{
Júlio Cesar Andrade de Abreu \\ Universidade Federal Fluminense (UFF) \\ José Antonio Gomes de Pinho \\ Universidade Federal da Bahia (Ufba)
}

\begin{abstract}
Este trabalho analisa três edições (2006, 2008 e 2011) do Orçamento Participativo Digital (OPD) de Belo Horizonte (MG). Objetiva deslindar os sentidos e significados da participação democrática mediada pela internet nessa experiência. Utiliza-se como método o estudo de caso único, de natureza qualitativa. Os dados foram coletados por meio de observação direta nos sítios do OPD e análise documental. Durante a fase de observação direta foram coletadas mensagens e manifestações dos cidadãos que estavam participando do processo. Tais dados foram tratados com o software Atlas TI 6.0®. Conclui-se que tanto o sentido quanto o significado democrático dessa experiência de participação mediadas pela internet são modificados ao longo das edições, indo de grandes impulsos de esperança democrática até a descrença nessa modalidade de participação digital.
\end{abstract}

Palavras-chave: participação; internet; democracia; orçamento participativo.

Sentidos y significados de la participación democrática a través de Internet: un análisis de la experiencia de Presupuesto Participativo Digital

Este trabajo analiza tres ediciones (2006, 2008 y 2011) del Presupuesto Participativo Digital (PPD) de Belo Horizonte (MG). Su objetivo es comprender el significado de la democracia y los significados de participación democrática mediadas por la Internet, en este experimento. Se utiliza como método el estudio de caso único, de naturaleza cualitativa. Los datos fueron recolectados en los sitios del PPD, con la observación directa y análisis de documentos. Durante la observación directa se recogieron los posts y las manifestaciones de los ciudadanos que participaban en el proceso. Los datos obtenidos fueron procesados a través del Atlas TI 6.0®. Llegamos a la conclusión de que tanto el significado y la importancia de esta experiencia de participación democrática mediada por las TIC, se modifican a

DOI: http://dx.doi.org/10.1590/0034-76121707

Artigo recebido em 2 set. 2013 e aceito em 7 abr. 2014. 
lo largo de las ediciones, que van desde grandes impulsos de esperanza democrática, aunque no creer en este tipo de participación digital.

Palabras clave: participación; internet; democracia; presupuesto participativo.

Senses and meanings of the democratic participation through the Internet: an analysis of the experience of Digital Participatory Budget

This paper analyzes three editions (2006, 2008 and 2011) of Digital Participatory Budget (DPB) of Belo Horizonte (MG). The objective is to understand the senses and meanings of the democratic participation mediated by the Internet in this experience. It is used the single case study method of qualitative nature. Data were collected through direct observation in DPB sites and document analysis. During the direct observation period, messages and manifestations of the citizens who were participating of the process were collected. These data were processed through the software Atlas TI 6.0®. We conclude that both democratic sense and meaning of this participation experience mediated by the Internet are modified throughout the editions, ranging from large impulses of democratic hope, up to disbelief in this type of digital participation.

KEYWORDs: participation; internet; democracy; participatory budget.

\section{Introdução}

Com a emergência da chamada "sociedade da informação" e a consolidação das tecnologias da informação e comunicação (TIC) no cotidiano da sociedade, muito se tem debatido sobre a possibilidade de ampliação da participação democrática dos cidadãos. A Internet, que foi "desenvolvida para a guerra, democratizada por hackers e absorvida pelo mercado", carrega em si grande potencial de fortalecimento democrático (Sampaio e Barros, 2011:87) e contrahegemônico. Percebe-se que a "internet pode ser colocada como um marco civilizatório: a vida antes e depois da internet, pois ela tem criado expectativas elevadas de mudanças, algumas até revolucionárias" (Pinho, 2011:98). A própria morfologia das sociedades se modifica, assumindo a forma de uma organização social em redes, "com isso, tudo se modifica - da experiência e da cultura ao poder e ao processo produtivo" (Nogueira, 2003:150).

Existe um crescente interesse na academia e na prática governamental em novas formas de relacionamento entre o Estado e a sociedade, principalmente no que tange aos processos de tomada de decisão pública (Cunha e Pozzebon, 2009). Ao mesmo tempo, alguns autores como Welp (2007) e Best e colaboradores (2010) reconhecem que poucos são os estudos sobre experiências governamentais de participação democrática mediadas pela Internet. É neste contexto que este trabalho busca investigar o Orçamento Participativo Digital (OPD) de Belo Horizonte (PBH), tentando contribuir com os estudos nessa área. Objetiva-se deslindar os sentidos democráticos e significados da participação democrática mediada pela Internet, dentro da experiência do OPD de Belo Horizonte, a partir da visão dos cidadãos. Por sentidos democráticos entendem-se aqui os julgamentos e sensos de juízo expressos pelos cidadãos em suas manifestações on-line sobre a experiência do OPD (Serafim, 2008). Já o significado 
democrático é aqui entendido como o tipo de democracia, ou modelo, que mais se aproxima dos sentidos expostos (Held, 2006).

Além desta introdução, o presente artigo debate a emergência da participação digital (e suas várias nuances) no segundo tópico. O terceiro tópico aborda a experiência do OP Digital. Em seguida, é detalhada a metodologia empregada. O quinto tópico apresenta os dados e a análise efetuada da experiência e, finalmente, o sexto tópico traz as observações conclusivas, indicações de futuras pesquisas e limitações deste trabalho.

\section{A participação na era digital}

A participação popular mediada pelas TIC é um fenômeno recente, segundo Sanford e Rose (2007). Apesar disso, esse tema tem sido pesquisado sobre diversos enfoques. Alguns autores (Aikens, 1998; Ainsworth, Hardy e Harley, 2005; Berman e Witzner, 1997; Dutta-Bergman, 2005) enfatizam a questão da infraestrutura e de temáticas sobre a exclusão digital. Para eles, as TIC têm seu desenvolvimento, como ferramenta participativa, condicionado à questão do avanço da inclusão digital da população. Sem essa condicionante, será impossível concretizar o potencial participacionista da Internet.

O debate sofre uma evolução para a temática da cidadania, no olhar de Chadwick e May (2003) e Hudson-Smith, Evans e Batty (2005). Na visão desses autores, além da infraestrutura, é imperativo o desenvolvimento de condições, na ferramenta internet, para o exercício cidadão. Existe uma grande diversidade de opiniões em torno desse exercício; entretanto, para todos os autores supracitados, as referidas condições devem ser oferecidas pelo governo, no ato da implementação das TIC na participação cidadã. O governo eletrônico é ainda um tema recorrentemente alçado em debates paralelos ao da democracia digital, ainda que em uma visão mais liberalista na qual a e-democracy é resumida aos serviços oferecidos pelo governo aos cidadãos (Knight et al., 2004; Moreno-Jimenez e Polasek, 2005; Lourenço e Costa, 2006).

A Internet e a participação eletrônica, em muitos trabalhos, são enfocadas como ferramentas e instrumentos para modalidades novas da administração (Bingham et al., 2005) e também para integrar grupos da sociedade civil (Chadwick, 2003). Um tema emergente trata das cidades digitais (Jambeiro et al., 2006). A administração é destacada nos estudos que se centram em serviços específicos nos quais os cidadãos são incluídos, como prática de accountability (Akutsu e Pinho, 2001), sistema de informação geográfica (Al-Kodmany, 2000; Elwood, 2001), processos de planejamento e integração de sistemas (Santos, 2008a, 2008b) e outras iniciativas de e-goverment (Knight et al., 2004; Moreno-Jimenez e Polasek, 2005; Lourenço e Costa, 2006). Já o papel da administração é discutido de forma mais ampla por Gimmler (2001), em um estudo que ilustra como as diferentes municipalidades desenvolveram serviços de e-democracy.

São inúmeros os estudos que discutem as várias formas como as práticas de participação na Internet são percebidas. Svensson e Leenes (2003) e Kenski (2005) destacam o voto 
eletrônico, mediado pela Internet (e-voting); Taylor e Burt (2005), Trench e O’Donnell (1997) e DeLuca e Peeples (2002) analisam o ativismo digital (e-activism) como prática decorrente do uso da Internet para organização e mobilização social para a participação cidadã; e ainda existem os trabalhos de Beynon-Davies e colaboradores (2004) e Chadwick e May (2003) que focam as consultas eletrônicas dos cidadãos (e-consultation). Esses exemplos ilustram como existe um amplo e rico campo em estudos de experiências diversificadas.

O potencial de transformação das TIC e, em especial, da Internet no desenvolvimento de iniciativas de participação eletrônica é sempre destacado por vários autores (Berman e Witzner, 1997; Hacker, 2004; Luhrs et al., 2003), mas poucos, ainda que tratem da participação e da cidadania, por exemplo, abordam a temática política ou mesmo a democracia eletrônica (Sanford e Rose, 2007).

\section{0 Orçamento Participativo: do presencial ao digital}

O Orçamento Participativo (OP) é a experiência de participação local mais pesquisada e discutida no Brasil. Fortemente identificado com o Partido dos Trabalhadores (PT) e com a cidade de Porto Alegre (tida como pioneira na implantação desta modalidade de participação), o OP, na atualidade, é vivenciado em centenas de municípios brasileiros (governados pelos mais diversos partidos políticos) e já ultrapassou, em muito, essa dimensão regional e de identificação partidária. Experimentado em cidades da Argentina, Uruguai, França, Espanha e outros diversos países, o OP é internacionalmente reconhecido como uma inovação democrática (Fedozzi, 2008, 2007; Avritzer e Navarro, 2003).

De acordo com Avritzer e Navarro (2003), o OP estrutura-se em quatro eixos: (a) inversão das prioridades de recursos públicos locais em prol das populações mais carentes; (b) autorregulação soberana, a partir da definição de regras e procedimentos pelos participantes do OP; (c) reintrodução de elementos de participação local (assembleias regionais, conselhos etc.), combinando-se com métodos de democracia representativa e participativa; e (d) cessão de soberania por quem detém o poder representativo local. O Orçamento Participativo pode ser definido como uma forma de "rebalancear a articulação entre a democracia representativa e a democracia participativa" (Avritzer e Navarro, 2003:14).

No período de 2001 até os dias atuais, vários estudos foram realizados e, segundo Avritzer (2009:19), desde 2004 “assistimos a um momento de redefinição do OP”. Esse processo teve início com a derrota do PT ao governo municipal de Porto Alegre e de São Paulo em 2004.

Essas características têm sido percebidas principalmente em cidades de médio porte com boa capacidade administrativa e tributária. Estudos sobre o perfil dos municípios que utilizam o OP (Fedozzi, 2007; Gonçalves, 2005; Avritzer, 2009) apontam cidades com mais de 100 mil habitantes, com uma sociedade civil relativamente organizada e, normalmente, governadas por partidos de esquerda, não necessariamente o PT. 
Outro ponto observado é a desconcentração das experiências do OP das regiões Sul e Sudeste do país. Cada vez mais cidades da região nordeste adotam o OP. Nos últimos 15 anos se presenciam os primeiros movimentos, no cenário brasileiro, de hibridização do OP com as tecnologias da informação e da comunicação. Diversos autores apontaram essa tendência (Santos, 2002; Dutra e Benevides, 2001; Sanchez, 2002).

Dutra e Benevides (2001) defendem que o uso de novas tecnologias é uma tendência, dada a necessidade de ampliar o OP para outras instâncias além dos municípios (como os estados, por exemplo). A criação de arenas virtuais de debate, na visão dos autores, poderia atrair mais pessoas para o processo participativo, no qual a tecnologia serviria à democracia.

Para Santos (2002), as tecnologias da informação e os processos de democracia eletrônica devem ser empregados para a criação de "custos diferenciados de participação" (Santos, 2002:550). Segundo o autor, "a introdução de referendos e o uso da democracia eletrônica (via internet) podem ser uma solução, desde que se determine o tipo de objetivos destas formas mais individualistas e menos intensas de participação" (Santos, 2002:550). Ou seja, a combinação de tecnologias de participação (como o OP) com as TIC seria necessária, na visão de Santos (2002), para que se diversifiquem os canais participativos, uma vez que, com o crescimento e o reconhecimento da eficácia do OP, ocorreria um aumento no volume de participação da população. Certamente o emprego de canais diferenciados poderia atender a uma demanda crescente por participação nos assuntos públicos (Santos, 2002).

Em 2001, na cidade de Ipatinga (MG), foi criado o Orçamento Participativo Interativo (Faria e Prado, 2003), que tornou possível a indicação de obras prioritárias para a cidade por meio de voto eletrônico via sítio do orçamento participativo.

Na esteira da inovação de Ipatinga, Belo Horizonte desenvolveu, em 2006, o OP Digital com uma proposta bastante distinta do OP Interativo e com muito mais visibilidade. Segundo Cunha, Allegretti e Matias (2007), a Internet era utilizada em Belo Horizonte, até o ano de 2006, apenas para divulgação de informações e mapas de obras realizadas pelas modalidades presenciais do OP. A partir do referido ano, os munícipes puderam escolher algumas obras predefinidas pela Prefeitura em conjunto com a Comforça (o conselho de delegados do OP). Ainda não existem, entretanto, muitos estudos profundos sobre essa experiência, mas se nota uma forte ampliação quantitativa na participação mediada pela Internet.

As duas iniciativas em cidades mineiras convergem para a visão de vários autores (Santos, 2002; Cunha, Allegretti e Matias, 2007; Sanchez, 2002; Dutra e Benevides, 2001), que defendem o uso conjunto do OP presencial e virtual. Tem-se o indicativo de um início de uma fase "digital" na história do OP.

\section{Metodologia}

A presente pesquisa utiliza como método o estudo de caso e sua natureza é qualitativa. Segundo Zanella (2009:75), esse tipo de pesquisa pode ser definido "como a que se fundamenta 
principalmente em análises qualitativas, caracterizando-se, em princípio, pela não utilização de instrumental estatístico na análise dos dados". Foram contempladas as edições 2006, 2008 e 2011 do OPD.

O campo de análise do caso sugere um dado recorte espaçotemporal. A análise empreendida tem como escopo espacial a cidade de Belo Horizonte (MG) e as experiências entre 2006 e 2011. Os dados foram coletados com observação direta no sítio do OP Digital da Prefeitura de Belo Horizonte, no período de 20 de novembro de 2008 até 10 de janeiro de 2009, para a edição 2008. Nessa observação, foram coletadas todas as postagens dos cidadãos que participaram da ferramenta "recados" do OPD, num total de 1.036 postagens, realizadas no período de 12 de novembro 2008 a 8 de dezembro de 2008. Na edição de 2011, o período de análise compreende o intervalo entre 21 de novembro de 2011 e 13 de dezembro de 2011, onde foram analisadas 1.258 postagens na ferramenta de recados do sítio. Quanto à edição 2006, foram analisadas 29 postagens no Fórum do OPD 2006 — únicas informações que ainda estavam disponíveis, quando esta pesquisa foi realizada, através de um sítio Archive Web.

Foi realizada também uma análise documental em diversos relatórios e documentos divulgados pela Prefeitura Municipal de Belo Horizonte.

Após a coleta dos dados, inicia-se a etapa seguinte: a análise das informações e dados. Segundo Miles e Huberman (1994), nessa fase, define-se qual é a abordagem empregada para identificar, codificar, analisar e interpretar os dados obtidos. Esse processo envolve basicamente extrair significados dos dados coletados.

O principal meio de organização dos dados se deu com o suporte do software Atlas TI 6.0®. ${ }^{1}$ Segundo Walter e Bach (2009:7), esse programa possui quatro princípios básicos, denominados Vise:

visualização: gerencia da complexidade do processo de análise, mantendo o contato do usuário com os dados; integração: a base de dados e todos os elementos construídos na análise são integrados em um único projeto, a unidade hermenêutica; casualidade (serendipity): promove a descoberta e os insights casualmente, isto é, sem a busca deliberada por aquilo que foi encontrado; exploração: a interação entre os diferentes elementos constitutivos do programa promove descoberta e insights.

Os elementos constitutivos do Atlas TI podem ser observados no quadro 1.

\footnotetext{
${ }^{1}$ Esse software foi desenvolvido para análise qualitativa de textos, imagens e sons, baseado na codificação prévia elaborada pelo pesquisador. Foram avaliados outros softwares para uso como o QSR NVIVOß e o QDA Miner $®$, nos aspectos de recursos e ferramentas de análise, facilidade de operação e custo de aquisição. O Atlas TI $®$, no entanto, mostrou-se mais adequado para esta pesquisa. A versão empregada foi a 6.0. Mais detalhes podem ser obtidos em: $<$ www.atlasti.com/ $>$.
} 
Quadro 1

Elementos constitutivos do Atlas TI $6.0{ }^{\circledR}$

\begin{tabular}{|c|c|}
\hline Elemento & Descrição \\
\hline $\begin{array}{l}\text { Unidade Hermenêutica } \\
\text { (Hermeneutic unit) }\end{array}$ & Reúne todos os dados e os demais elementos. \\
\hline $\begin{array}{l}\text { Documentos primários } \\
\text { (Primary documents) }\end{array}$ & $\begin{array}{l}\text { São os dados primários coletados. Em geral, são transcrições de entrevistas e notas de } \\
\text { campo, mas suportam figuras e áudio. Na presente pesquisa, foram utilizadas as postagens } \\
\text { e manifestações dos cidadãos nos sítios do OPD, e análise documental. }\end{array}$ \\
\hline $\begin{array}{l}\text { Citações } \\
\text { (Quotes/quotation) }\end{array}$ & $\begin{array}{l}\text { São segmentos de dados, como trechos relevantes das entrevistas que indicam a } \\
\text { ocorrência de código. }\end{array}$ \\
\hline $\begin{array}{l}\text { Códigos } \\
\text { (Codes) }\end{array}$ & $\begin{array}{l}\text { São os conceitos gerados pelas interpretações do pesquisador. Podem estar associados a } \\
\text { uma citação ou a outros códigos para formar uma teoria ou ordenação conceitual. }\end{array}$ \\
\hline $\begin{array}{l}\text { Notas de análise } \\
\text { (Memos) }\end{array}$ & $\begin{array}{l}\text { Descrevem o histórico da pesquisa. Registram as interpretações do pesquisador, seus } \\
\text { insights ao longo do processo de análise. }\end{array}$ \\
\hline $\begin{array}{l}\text { Esquemas gráficos } \\
\text { (Netview) }\end{array}$ & $\begin{array}{l}\text { Esta ferramenta auxilia a visualização do desenvolvimento da teoria e atenua o problema } \\
\text { de gerenciamento da complexidade do processo de análise. Os esquemas gráficos são } \\
\text { representações gráficas das associações entre códigos. }\end{array}$ \\
\hline $\begin{array}{l}\text { Comentários } \\
\text { (Comment) }\end{array}$ & $\begin{array}{l}\text { Podem estar presentes em todos os elementos constitutivos. Devem ser utilizados pelos } \\
\text { pesquisadores para registrar informações sobre seus significados, bem como para registrar } \\
\text { o histórico da importância do elemento para a teoria em desenvolvimento. }\end{array}$ \\
\hline
\end{tabular}

Fonte: Walter e Bach (2009:8).

Segundo Barbosa (2008), que empregou um software similar em uma pesquisa, esse tipo de programa destina-se principalmente ao armazenamento e gerenciamento de segmentos de textos codificados. Cabe lembrar que, embora o software ajude sobremaneira na organização dos dados, a responsabilidade de análise, codificações, interpretações e conclusões é sempre do pesquisador (Barbosa, 2008; Canção, 2006).

A organização e a análise dos dados se deram por meio da criação de unidades hermenêuticas (HU), dentro do Atlas TI 6.0®, para cada edição do OPD, compostas pelas fontes primárias da pesquisa. Em seguida, essas fontes foram analisadas e codificadas. Procedeu-se uma comparação dos segmentos de dados codificados. Os documentos e elementos que emergiram da análise (códigos e memos) foram organizados em famílias. Finalmente foi construída uma netview semântica terminológica, que possibilitou atingir o objetivo proposto neste artigo.

\section{Analisando os discursos dos cidadãos no OP Digital}

Para termos um mapeamento das discussões que ocorreram nas três edições do OPD, realizamos uma leitura das postagens e a criação de códigos, com o apoio do software Atlas TI $6.0^{\circledR}$, 
a partir dos dados (bottom-up, grounded). Os códigos foram criados para operacionalizar as análises nesta pesquisa. As postagens foram agrupadas de acordo com seu significado e esse, por sua vez, foi codificado para que possibilitasse a correlação e a associação entre os sentidos das manifestações dos cidadãos. Todas as postagens foram lidas, porém somente aquelas com maior destaque dentro de seu grupo de codificação, ou seja, as mais contundentes é que foram transcritas para o texto deste artigo. Cabe lembrar que as postagens foram transcritas sem qualquer ajuste em termos ortográficos ou gramaticais. Tal decisão, de transcrição ipsis litteris, se justifica pelo respeito aos cidadãos que as postaram, ainda que com falhas gramaticais ou de concordância.

Tal mapeamento é necessário para que se perceba a evolução da dinâmica do OPD ao longo das diferentes edições. Uma vez apreendida a dinâmica do OPD, é possível realizar análises mais contextualizadas sobre o sentido e o significado democrático atribuídos pelos cidadãos. No caso da edição 2006, a análise dos diferentes códigos revelou a seguinte rede relacional:

Detalhando esta rede, nota-se um aglomerado de manifestações envolvendo os sentidos da participação, da política, da democracia e da cidadania que se vinculam a outras manifestações codificadas como "esperança". Nesse code foram colocadas as postagens dos cidadãos interpretadas como sentimentos de expectativa positiva sobre o OP Digital. A crença em resultados positivos e em benefícios para a sociedade a partir da então inovadora ferramenta de participação foi agrupada sob esse código. Nota-se que esse código se associa a outro conjunto de manifestações, que foram os elogios ao governo.

Diversas foram estas postagens elogiosas, como no exemplo abaixo:

Gostei muito da ideia do Prefeito de Belo Horizonte. Gostaria de parabeniza-lo pelo maravilhoso trabalho e dizer que fico orgulhosa quando vejo os avanços da cidade. Parabéns que Deus continue te iluminando para que voce possa ajudar a todos e melhorar ainda mais a nossa cidade. São politicos como Voce que nosso BRASIL precisa. (Postagem n. 143, OPD 2006)

Este tipo de manifestação conviveu lado a lado com algumas críticas, em menor número, sobre o OPD e o governo.

Meu nome é Leonardo Moreli, sou ambientalista e atualmente moro na cidade de Itu-SP. Por aqui entramos numa luta muito dura contra a corrupção na Prefeitura, desde que descobrimos as maracutaias do atual prefeito (eleito pelo PV com nosso apoio), a partir da luta contra a privatização da água. (Postagem n. 085, OPD 2006)

É interessante notar que, a palavra "corrupção" surge apenas no OPD 2006. Talvez os filtros/moderação, aplicados nas demais edições, evitaram esse tipo de palavra e mesmo ataques e palavras de baixo calão no debate. 


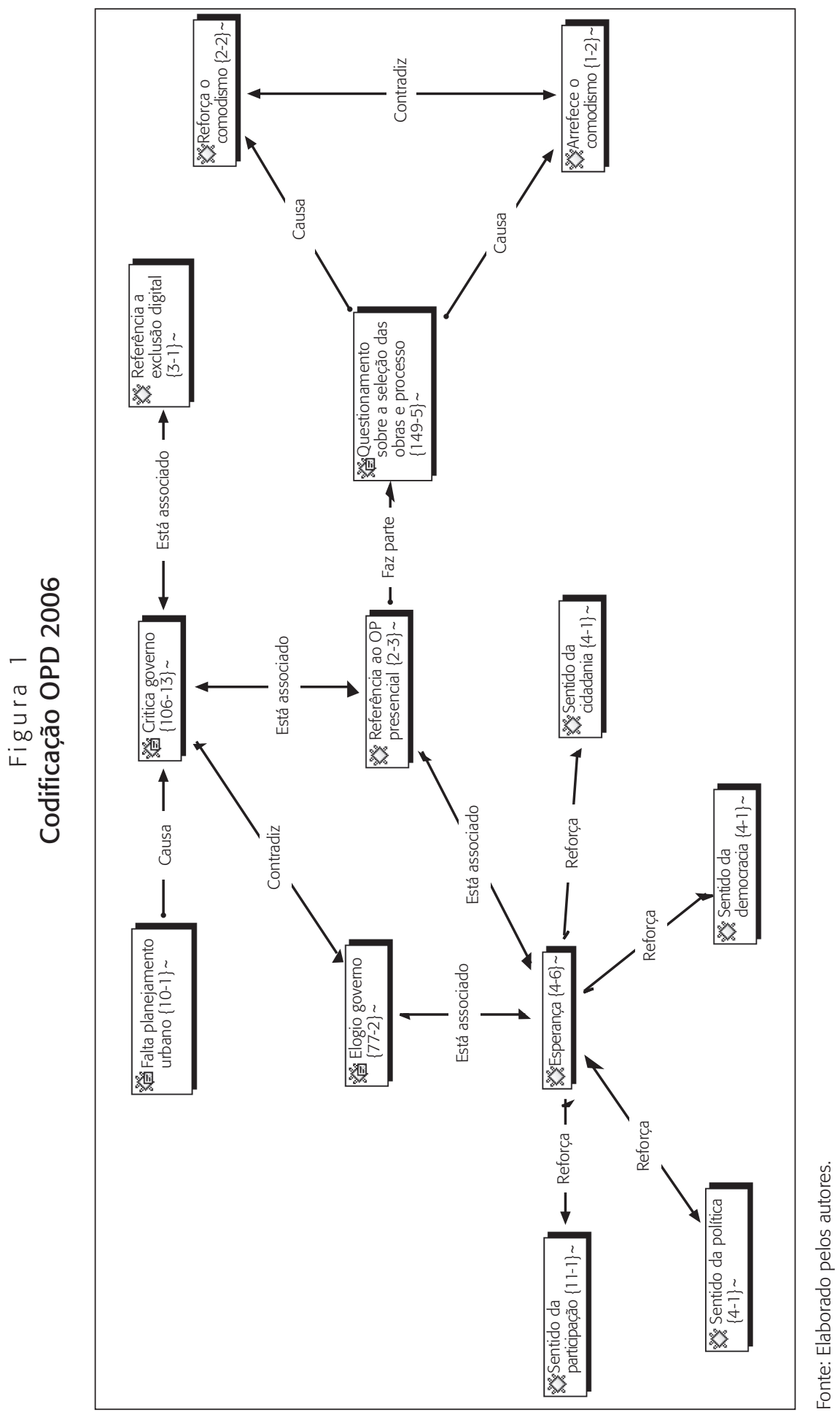


As críticas ao governo estavam associadas a alguns problemas e reclamações sobre infraestrutura urbana e também sobre a questão da exclusão digital. A seguir, vemos um exemplo de postagem sobre reclamações de infraestrutura e da exclusão digital, respectivamente.

COMCORDO PENA QUE NEM TODOS TEM ACESSO A INTERNET PARA PODEREM AJUDAR TAMBEM A DESCUTIR O QUE SERIA MELHOR PARA CADA REGIONAL. (Postagem n. 017, OPD 2006)

Vale salientar que, no debate da edição 2006, a questão da exclusão digital apareceu com mais destaque do que nas demais edições, certamente porque a inclusão digital progrediu aceleradamente nesses anos seguintes. Outro elemento que emergiu com muita força no debate de 2006 foi o que classificamos com o código "Esperança". Trata-se de um conjunto de manifestações por meio das quais os cidadãos demonstravam crença no poder transformador do OP Digital. Ao mesmo tempo, esse tipo de manifestação reforçou os sentidos com que a democracia, a participação, a cidadania e a política foram traduzidas nas postagens.

As manifestações codificadas como "Esperança" faziam referência, em alguns casos, a experiências de movimentos sociais, em uma clara alusão a um novo mundo que estaria nascendo:

Quem convive com movimentos sociais como o da ASMARE percebe na pele que esta nova cultura, redentora, está sim nascendo, surgindo e se sedimentando. (Postagem n. 104, OPD 2006; grifos adicionados)

Tenho recebido e-mails de diversos contatos meus na Europa interessados no que está acontecendo aqui em BH! Eles têm uma grande esperança em uma "nova forma de democracia que está surgindo no Brasil”. (Postagem n. 114, OPD 2006; grifos adicionados)

Juntamente com um esperançoso desejo de uma nova forma de democracia, o OPD em sua primeira edição despertou um sentimento de orgulho, como se observa a seguir:

Cidadãos Belo Horizontinos e autoridades municipais, é hora de vestirmos a camisa do OP digital, melhorá-lo continuamente, para que seja a marca e a contribuição de BH para este novo mundo, mais justo e solidário, que todos sonhamos e que está surgindo, em seu tempo, mais devagar do que gostaríamos, mas que, sim, está surgindo. (Postagem n. 116, OPD 2006)

E um desejo de ampliação do alcance desta iniciativa:

Espero que o orcamento participativo se amplie e cresca dentro do orcamento total da $\mathrm{PBH}$. (Postagem n. 208, OPD 2006)

O código "Esperança" das manifestações registradas na primeira edição do OPD mostrou-se determinante para o engendramento do sentido e dos significados democráticos assumidos. 
Para Santos (2002), trata-se de pensar em custos de participação diferenciados. Segundo o autor, se imaginarmos uma ampliação da participação em uma experiência de OP, teremos vários grupos sociais diferentes se mobilizando por objetivos diferentes. Desse modo, teríamos um dilema, pois só seria possível ampliar a participação até certo limite, dado que os objetivos competitivos seriam mais numerosos (Santos, 2002:550).

Usando o pressuposto de que mais participação é sempre melhor do que menos participação (Santos, 2002), o uso combinado de diferentes modalidades de participação, com diferentes custos, surge como um caminho para ampliação da participação em experiências como o OPD combinado com o OP Presencial. Nesse sentido, a manifestação da postagem 26, descrita a seguir, reforça o argumento de Santos (2002) de que novos públicos podem ser incorporados quando novos custos são testados no processo participativo. O cidadão, ao afirmar que "nunca tive a oportunidade de votar em OP achei bastante interessante" (Postagem n. 26, OPD 2006), não deixa claro o motivo da não participação.

Enquanto o OP Regional demanda aproximadamente oito meses de debates, deslocamentos físicos para assembleias, votações, eleições de representantes etc., o OP Digital mostra-se muito mais prático e com uma necessidade de investimento pessoal (tempo, disponibilidade para debater etc.) muito menor. Esse é um debate central, pois não é apenas uma relação de custo $\times$ benefício, mas envolve componentes que definem o que é um debate presencial e o que é um debate virtual com ganhos e perdas para as duas formas (Pinho e Winkler, 2009).

Contudo, a postagem 215 lança reflexões muito provocativas: "como que pessoas que não se dignam nem a sair de casa para conhecer o bairro vão ter discernimento para votar? Principalmente em obras dos outros bairros.”. (Postagem n. 215, OPD 2006). De fato, pensar a participação nesse contexto somente faz sentido de maneira combinada com outra modalidade democrática mais intensa (Santos, 2002).

A referência ao OP Regional relaciona-se com outro tipo de manifestação identificado: o questionamento quanto ao processo de seleção das obras que compuseram o rol de opção do OP Digital.

(...) Só queria registrar que o orçamento participativo digital tem algumas falhas, claro é a primeira vez que acontece. Por exemplo quem propõe as obras para a votação? Não foi a população que definiu, como é feito no op tradicional. Penso que se a população pudesse sugerir obras para a votação, o processo seria mais democrático. (Postagem n. 259, OPD 2006; grifos adicionados)

Tais questionamentos encontram eco na ideia de que existe um risco de arrefecimento da participação presencial e reforço do que os manifestantes chamaram de comodismo:

Meu nome é Elizabeth, sou lider comunitária e fui delegada no OP presencial. Acho válida a iniciativa da administração municipal na implantacão do OP digital, já que a maioria da populacão ou não tem tempo, ou é comodista ou apenas não se interessa. É uma pena, porque 
somente no OP presencial se tem a chance de conhecer melhor o processo e verificar os vários problemas que a sistemática impõe aos delegados, pessoas abnegadas que não se limitam a ficar em casa votando pela internet. (Postagem n. 215, OPD 2006; grifos adicionados)

Ao mesmo tempo, algumas postagens reconhecem o mérito de inserção de novos atores no processo de deliberação do OPD:

A iniciativa pioneira do Orçamento participativo é fascinante. É preciso lembrar que, se por um lado muita gente não tem acesso à internet para poder votar, o OP tem aumentado a participação popular entre aqueles que nunca sairam de suas casas para participar das reuniões das regionais por puro comodismo/falta de tempo/outros motivos. Além disso, a prefeitura está disponibilizando postos de votação em locais públicos, como o mercado central. Ou seja, o boca-a-boca permite que quem não tenha internet em casa possa participar ainda de alguma forma. (Postagem n. 245, OPD 2006; grifos adicionados)

Podemos delinear, a partir desse painel que emergiu da análise das postagens no sítio do OPD 2006, um cenário em que os cidadãos depositavam esperanças e credibilidade no processo. Houve uma substituição das reuniões presenciais, o que significa uma intermediação que não exige contato direto entre os munícipes e diminui custos de participação (Peixoto, 2009).

Foi evidente, nas postagens no sítio do OPD 2006, o sentimento de empoderamento (o cidadão percebe que sua participação faz a diferença), que faz vislumbrar a ampliação dessa participação para outros níveis. A seguir, algumas postagens que reforçam essa ideia:

Excelente essa idéia de OP digital! Acredito que com isto teremos uma maior participação da população, pois permite que todos tenham acesso aos projetos em votação. O sitio está muito fácil de utilizar! Parabéns!! Aguardo anciosamente pelo OP 2008!! Gostaria que os governos federal e estadual adotassem esta idéia! Seria ótimo para todos!! (Postagem n. 179, OPD 2006; grifos adicionados)

O OP digital de 2008 mudou radicalmente sua proposta em comparação com a edição de 2006. Em vez de uma obra por regional, foram colocadas para eleição cinco grandes obras para o sistema viário da cidade de $\mathrm{BH}$. A mudança permitiu o uso do telefone, um número 0800, como canal de votação, uma vez que o rol de opções foi reduzido, viabilizando a votação via telefone.

As discagens foram gratuitas (0800 723 2201) e sem nenhuma restrição referente ao tipo de aparelho que originava a ligação, mas sim quanto ao local de origem da ligação apenas as provenientes de localidades com código telefônico 031. (Prefeitura de Belo Horizonte, 2008:7)

Ao se analisarem as postagens dos cidadãos na ferramenta de recados do sítio, por meio de um processo de codificação a partir dos dados (bottom-up, grounded), obteve-se a seguinte rede relacional de códigos. 


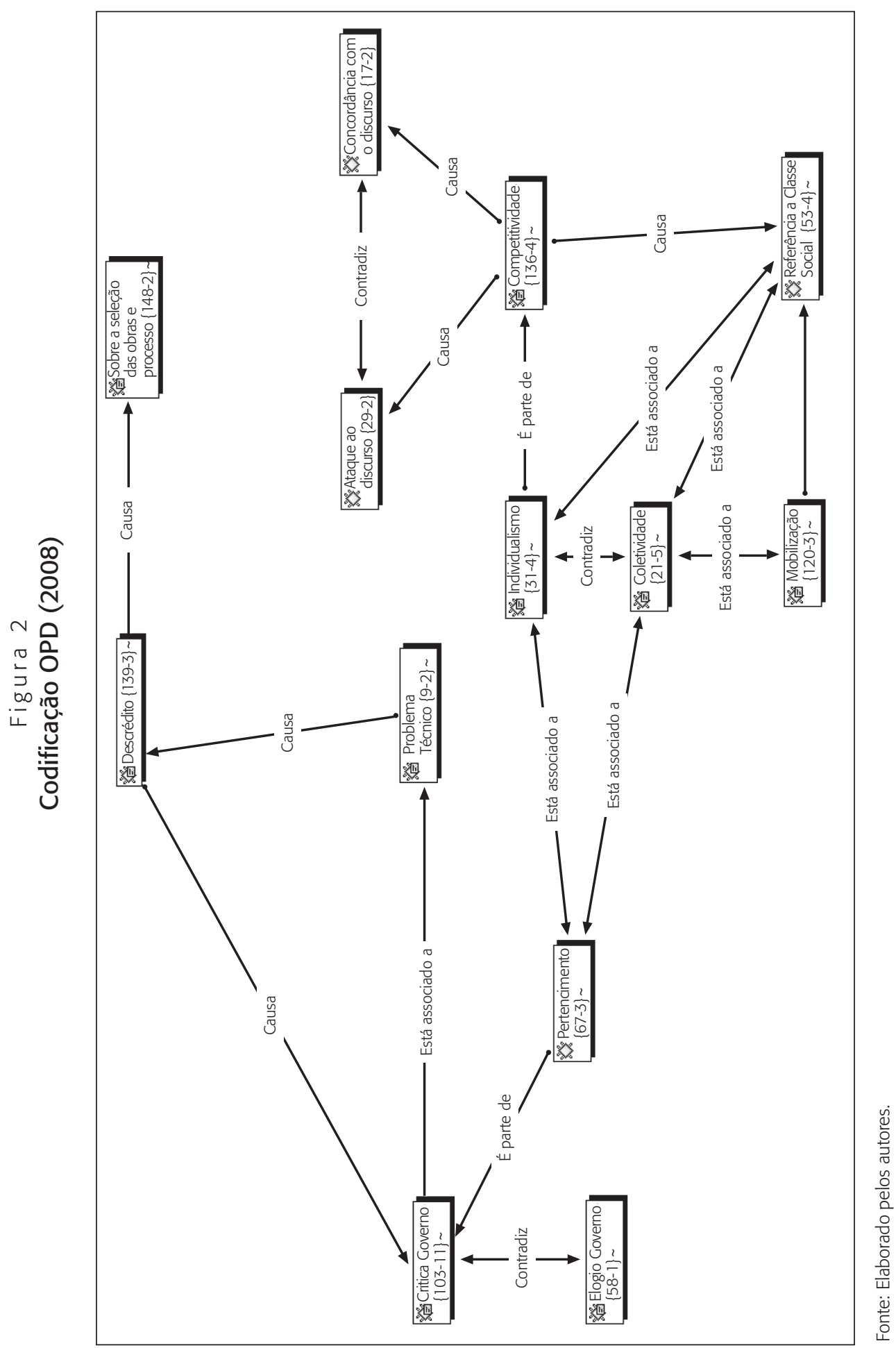

Rev. Adm. Pública - Rio de Janeiro 48(4):821-846, jul./ago. 2014 
Na rede relacional do OPD 2008, os diferentes codes estão mais pulverizados do que em comparação com a edição 2006. Nota-se forte concentração nas "referências a classe social", que causaram "mobilização"; estava associada à "coletividade" e ao "individualismo" e era causada pela "coletividade".

Várias manifestações questionavam a seleção das obras e mesmo o processo do OPD. Foram identificadas postagens questionando desde pontos operacionais até o prazo de votação:

Eu acho que o OP Digital deveria ser prolongado por mais uns 15 dias, pois nem toda a populaçao está ciente. Grato Tiago (Postagem n. 136, OPD 2008)

E, até o processo em si:

Acho que a votação não deveria ser para a construção de somente uma obra. Devíamos estar votando qual a obra vai sair primeiro. BH esta precisando urgente de todas estas obras (Postagem n. 242, OPD 2008)

Muitas pessoas postavam sugestões na ânsia de serem ouvidas pela Prefeitura, o que não ocorria dada a natureza "monológica" da ferramenta de recados. O objetivo era disponibilizar um canal de expressão, mas o feedback da PBH não era garantido, aliás, não existia a possibilidade de um diálogo, como em um blog, mas simplesmente de postagem de mensagens:

DEVERIA HAVER SEGUNDO TURNO SE NÃO FOSSE CONQUISTADO MAIORIA ABSOLUTA. (Postagem n. 617, OPD 2008)

Houve uma manifestação relacionada com um tipo de descrédito do OPD. O cidadão questiona a inserção de uma obra no rol de opções e faz uma relação com o OPD 2006 e também com uma promessa política:

A obra 1 é uma necessidade e promessa a anos. Esta obra participou do OP digital 2007 e ficou em $2^{\circ}$ lugar. Este ano pelo complexidade das obras concorrentes, também não será escolhida. Na proposta do "corta caminho" da prefeitura esta obra foi definida como uma das prioritárias (via710). Então por que está participando do OP digital 2008? (Postagem n. 272, OPD 2008)

O volume de críticas ao governo aumentou em comparação com a edição 2006. Mesmo existindo grande discrepância entre o volume de postagens das duas edições, nota-se que o tom dos comentários trazia críticas à Prefeitura ou diretamente ao prefeito. Outras faziam referência à aplicação dos recursos públicos:

(...) A praca S. Vicente, nos horarios de pico forma um grande GARGALO que castiga de forma CRUEL quem passa pelo trecho. Tem dó de nos Pref. Marcio Lacerda. (Postagem n. 595, OPD 2008; grifos adicionados) 
Ao mesmo tempo, vários elogios foram tecidos. Pela natureza das postagens, fica clara uma "transferência de crédito político" do então prefeito Fernando Pimentel (em final de mandato) para Márcio Lacerda (candidato apoiado por Pimentel). Algumas postagens faziam menção direta ao prefeito Pimentel:

ESTA OBRA É DE MUITÍSSIMA IMPORTÂNCIA PARA MILHARES DE MORADORES DE VÁRIOS BAIRROS. BH NUNCA TEVE UM PREFEITO COMO PIMENTEL, PARABÉNS PREFEITO. (Postagem n. 31, OPD 2008)

Outras deixavam evidente sua preferência eleitoral:

Esta obra valorizará sobremaneira a região, valorizando tambem, nós, muradores dos bairros envolvidos, acesso ao mineirão, zoológico, ceasa, etc. Parabens ao Pimentel por idealizá-la e ao Marcio, que com certeza, a realizará. (...) (Postagem n. 74, OPD 2008; grifos adicionados)

Um aspecto que chamou a atenção no debate do OPD 2008 foi codificado como "Pertencimento". Por conta de uma obra ser interpretada como benéfica para o município de Nova Lima, na região metropolitana de $\mathrm{BH}$, houve várias manifestações contra ela. Algumas pessoas defendiam que Nova Lima deveria contribuir de algum modo com a obra. Outros realizavam ataques, mais diretos, criticando o "crescimento desordenado" da cidade vizinha:

Essa é uma obra que beneficia mais Nova Lima que BH. Se NL permite a ocupação deseordenada que gerou o aumento de tráfego na região, não é justo que $\mathrm{BH}$ arque com os custos desse acesso. Além disso, tal obra é indiferente para quem usa o transporte coletivo. As intervenções nas outras regionais, em especial Pampulha e Noroeste apresentam maior público a ser favorecido. (Postagem n. 254, OPD 2008; grifos adicionados)

Tal situação gerou um debate. Um grupo criticando a obra n. 1, que beneficiaria a cidade de Nova Lima, vizinha e contígua a $\mathrm{BH}$, outro defendendo tal situação e, ainda, um terceiro grupo reclamando, pois não eram eleitores de $\mathrm{BH}$ e, como tal, não poderiam votar no OPD. Exemplificamos a seguir com duas postagens, nas quais se defende a obra 1 e, em seguida, uma postagem de um cidadão que não era eleitor de $\mathrm{BH}$ que reivindicava o direito de voto no OPD:

Àqueles que afirmam que esta obra só beneficiará Nova Lima só tenho a dizer que não conhecem a realidade da região que separa os dois municípios. A verdade é que diversos moradores da região trabalham em $\mathrm{BH}$ e alguns de $\mathrm{BH}$ trabalham em Nova Lima. Assim, se a obra tem por objetivo beneficiar a população de $\mathrm{BH}$, que atualmente é muito prejudicada pelos constantes engarrafamentos na região (...). (Postagem n. 400, OPD 2008)

Essa obra é essencial para a vida de todos que moram e trabalham em torno da região. Vale lembrar que a discussão sobrepõe o domínio territorial: se é Nova Lima ou BH. É uma região de 
interesse geral onde temos a localização de um centro comercial enorme sem contar faculdades, hospitais. Temos ganhar essa obra! (Postagem n. 385, OPD 2008)

Fiquei triste por não poder votar devido a não ser eleitor em BH, fato que acho irrelevante pois como eu varias pessoas por razões diversas vivem em BH e não são daqui. Fora isto, sou mineiro e me acho no direito e dever de opinar sobre o futuro de nossa capital. (Postagem n. 57, OPD 2008)

A competição nesta edição se mostrou muito acirrada. Várias foram as manifestações que possuíam características classificadas com o código de "Individualismo":

(...) Cada um defende a obra que achar melhor, apenas isso. Minha família e eu votamos na obra 5. Moramos na região noroeste, conhecemos os problemas dessa região, passamos por esse trajeto todos os dias. Se temos a oportunidade de melhor pra nós, é claro que vamos fazer de tudo para que consigamos. (Postagem n. 17, OPD 2008; grifos adicionados)

Acirrou-se uma grande competição entre os cidadãos no processo de votação. Principalmente em torno das obras n. 5 (praça São Vicente com anel rodoviário) e n. 4 (Portal Sul/ Belvedere). No debate, a primeira ganhou status de obra "popular", enquanto a segunda passou a ser vista com obra da "elite", além de ser relacionada como beneficiária do município de Nova Lima. A obra n. 4 liderava a votação, mas uma grande mobilização em torno da obra $n$. 5 conduziu uma virada na votação e consolidou a praça São Vicente com anel rodoviário como vencedora. A competitividade pode ser retratada por postagens como:

AS PESSOAS DEVEM TIRAR DA CABEÇA QUE OBRAS DA ZONA SUL BENEFICIAM QUEM TEM PODER AQUISITO MAIOR. ISSO É PRECONCEITO! ESSA MELHORIA DE TRANSITO DEVE SER EFETUADA POIS TEM GENTE DE BHTE QUE TRABALHA OU ESTUDA EM NOVA LIMA E VICE VERSA. O QUE IMPORTA É QUE DEVEMOS DAR SOLUÇÃO AO TRÂNSITO NESTA REGIÃO, QUE JÁ ESTÁ PRECISANDO DESTA MELHORIA DEMAIS, POIS ESTÁ INSUPORTÁVEL. BELVEDERE É BELO HORIZONTE TAMBÉM. (Postagem n. 510, OPD 2008; grifos adicionados)

A OBRA QUE NO MOMENTO ESTA EM PRIMEIRO LUGAR ATENDE SIM O APELO DA POPULAÇAO, MAIS DA POPULAÇAO RICA E ABASTARDA DE BH. AS OUTRAS OBRAS SAO DE UMA IMPORTANCIA MAIOR PARA A POPULAÇAO DE CLASSE MEDIA BAIXA DA CAPITAL, POIS OS RICOS DA ZONA SUL, PODEM ATE COMPRAR HELICOPTEROS PARA SE LOCOMOVER NA CAPITAL, MAIS COMO QUE PARECE SER O ERRADO, CERTO, E O CERTO, ERRADO, OS RICOS QUE TEM ACESSO MAIOR A INTERNET. (Postagem n. 563, OPD 2008; grifos adicionados)

Em pouco tempo o debate começou a fazer referência a classes sociais, protagonizando, em alguns momentos, uma disputa entre ricos e pobres: 
Realmente. $\mathrm{E}$ a velha diferença entre região rica e pobre. TODOS AVISARAM QUE A OBRA 4 VAI SAIR DE TODO JEITO, A CAMARA JA APROVOU A OBRA. PORTANTO É MAIS RECIONAL (SEM CONTAR OS OUTROS FATORES) VOTAR NA OBRA № 5, PORQUE ASSIM TODA A CIDADE GANHA, PQ SAEM ASSIM AS 2 OBRAS É QUESTÃO DE LÓGICA. (Postagem n. 210, OPD 2008; grifos adicionados)

Todos têm o direito de batalhar para que a sua obra seja a escolhida, portanto pessoal, vamos subir o nível da discussão e fazer comentários realmente relevantes. Basta dessa guerrinha entre ricos e pobres. A questão não é essa e sim qual a obra que favorecerá um número maior de cidadãos. (Postagem n. 378, OPD 2008; grifos adicionados)

O debate começa a reverberar o que estava ocorrendo no mundo presencial: mobilizações, panfletagem e organização de pessoas em torno da votação.

Pessoal... Pessoal... o povo da ZONA SUL vai fazer mutirão nestes dias 06/ 07 e 08/12 para tentar superar a massa. Pessoal vamos nos unir mais ainda para dobrar a votação e mostrar a falta de humildade e reconhecimento de uma região abastarda de lazer, diversão e ótimas infraestruturas que visão a comodidade e não o simples e necessário que tanto almejamos. Ser justos e olhar para os necessitados. (Postagem n. 45, OPD 2008; grifos adicionados)

Como foi dito, a obra n. 5 reverteu o placar negativo e venceu a disputa, por conta de uma grande mobilização popular e também de um canal de votação muito importante: o telefone. A obra vencedora contou com mais de $12 \%$ dos votos oriundos do telefone, através de um número 0800 disponibilizado pela $\mathrm{PBH}$.

Nota-se que o uso do telefone oportunizou a um grupo de pessoas com acesso restrito à Internet a participação massiva no processo. No debate on-line, a questão do acesso à Internet foi associada à região e à renda, fazendo com que pessoas identificassem os beneficiários diretos da obra n. 4 como possuidores de melhor acesso à rede:

EU não moro na Noroeste, mas votei nessa obra por achar que é a que vai apresentar maior público beneficiado. Sei que o povo da centro-sul tem mais acesso à internet, tanto que a obra de lá tá ganhando. Estou divulgando o telefone 0800-723 2201 para meus conhecidos votarem no OP. Muita gente não sabe desse telefone porque a PBH divulga só a internet. Divulguem vocês também o telefone pra todos. (Postagem n. 429, OPD 2008)

Como sempre acontece a região mais favorecida se beneficia em detrimento as mais necessitadas. $\mathrm{O}$ acesso a internet e as informações como são maiores nestas regiões mais ricas possibilitam maior acesso e em decorrência disso maior votação. Espero que o OP atinja também as áreas onde realmente se necessita urgentemente de obras, como é o caso do cruzamento do Anel Rodoviário com Av. Tereza Cristina. (Postagem n. 548, OPD 2008) 
No final, a obra n. 5 venceu, com grande mobilização popular, mas não foi implementada até o início da edição 2011 do OPD. Segundo a Prefeitura, a obra foi incorporada a um projeto do governo federal. A obra que ficou em segundo lugar (obra 4) já foi implementada e está concluída. A PBH informa que a obra n. 4 não foi realizada com recursos do OPD 2008, conforme nota divulgada no sítio do OPD.

Obra vencedora "Praça São Vicente" foi incorporada ao Projeto de Revitalização do Anel Rodoviário após a votação, e será realizado pelo Governo Federal. A Prefeitura de Belo Horizonte esclarece que não investiu nenhum recurso na obra do Portal Sul/Belvedere que concorreu no OP Digital 2008. A obra que está sendo realizado neste é de responsabilidade da Empresa Leroy Merlin, de acordo com a contra partida definida pelo Licenciamento Ambiental.

O fato de a obra vencedora não ter sido realizada no OPD 2008 deu o tom do debate na edição de 2011, quando o modelo de obras por regional foi retomado. O governo municipal sofreu várias críticas e muitas manifestações de descrédito ocorreram no OPD 2011.

A figura 3 traz um mapeamento do debate com as mensagens postadas no sítio do OPD 2011.

A "crítica ao governo" centralizou majoritariamente os codes da edição 2011 do Orçamento Participativo Digital.

Muitas foram as manifestações codificadas como "falta" de algo. Muitas pessoas reclamavam de falta de cultura, de educação, de transporte, de saúde, de segurança, de planejamento urbano e de lazer. Seguem alguns exemplos dessas postagens:

A região de Venda Nova é muito carente de um espaço cultural p/ esposições, museus, praças esportivas, etc... (Postagem n. 72, OPD 2011)

Cultura é civilização, quem sabe este espaço possa atender crianças e jovens que gritam por socorro ao não terem o que fazer e encontram a rua como única forma de aprendizado, já que nas escolas pouco se aprende com referência ao respeito, a dignidade e a descoberta de talentos. (Postagem n. 290, OPD 2011)

O governo municipal acabou sendo alvo de muitas críticas, em alguns casos, associadas à eleição de Márcio Lacerda, sugerindo que, diferente da edição 2006 que arregimentou votos para o candidato do governo, desta vez ocorreu o oposto:

So vejo obras de recapeamento de asfalto. A Prefeitura acredita que é somente isso que o Barreiro precisa? Para as pessoas que estão votando, pensem na saude, na segurança, educação e nas necessidades de locomoção antes de votarem em simples recapeamento de asfalto. Para o Prefeito: Isso não é lucro. É migalha que vocês estão oferecendo para a população. Nessa hora me pergunto: para onde vão os milhões que pagamos em impostos? (Postagem n. 1.145, OPD 2011, grifos adicionados) 


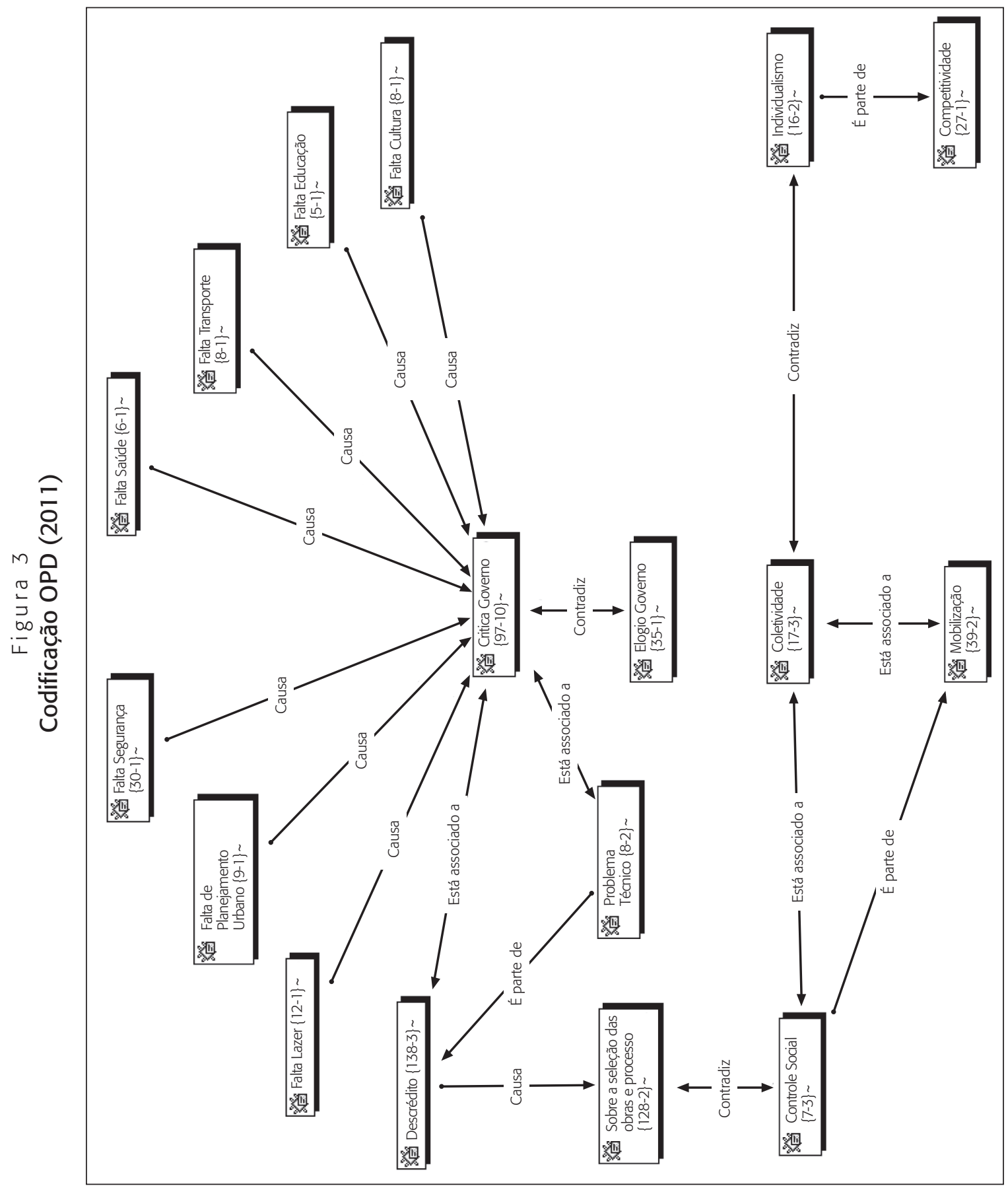

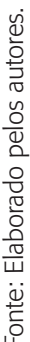


Em outros casos, as críticas se dirigiam ao processo, questionando o rol de obras disponíveis para votação:

É uma vergonha apresentar esse nível de obras para população votar. Só tem projetos de maquiagem, nenhum realmente expressivo que vá trazer benefícios reais a nenhuma região. (Postagem n. 373, OPD 2011)

Penso que é uma vergonha, colocar tais obras em votação, uma vez que é de responsabilidade da prefeitura, com o pretexto de se estar fazendo uma gestão democrática; democratizando as verbas públicas. (Postagem n. 06, OPD 2011; grifos adicionados)

Com a mudança do sistema de votação, foram solicitados cadastros adicionais para que as pessoas efetuassem a votação. Tal iniciativa teve como objetivo ampliar a segurança do processo. Isso de fato ocorreu, porém problemas técnicos foram identificados e expressos no sítio pela população. E isso foi mais um elemento que contribuiu para reforçar as críticas à $\mathrm{PBH}$ :

Não consegui votar pois os caracteres para maior seguraça não consegui dijitar. (Postagem n. 705, OPD 2011)

Uma onda de manifestações de descrédito com relação ao OPD foi identificada. Fruto, principalmente, da não realização da obra vencedora na edição de 2008, o descrédito na edição 2011 ocupou importante espaço nas manifestações.

ESTA OP DIGITAL E SO PARA ENGANAR O ELITOR/CONTRIBUINTE, NAO FAZEM NADA DO QUE GANHAM E AINDA TEMOS QUE OUVIR QUE UM DIA VAI FAZER. (Postagem n. 467, OPD 2011)

Estou decepcionado com este governo municipal, pois lutei pela obra da praça São Vicente que era de responsabilidade da PBH, agora é do DNIT, que nao sai do papel; sou solicitante da UPA NOROESTE, já tem a empresa que executar o projeto, mas o prefeito nao desapropriou o local que indiquei, nem chama para discutir, assim fica dificil participar, nao estamos estimulados com este retardamento e falta de clareza da prefeitura. Nao esquecendo do BRT das avenidas Dom Pedro II e Presidente Carlos Luz, que o prefeito vetou para atender os empresários destas vias, prejudicando a massa usuária de transporte por onibus, pois sofremos com engarrafamentos. Tá dificil pedir votos, pois as comunidades estão revoltadas com tantos descasos, não sei se vou votar!!! (Postagem n. 469, OPD 2011)

Acho que de nada vale o O.P., lembro bem de um que teve que era a restruturacao da Pca. Sao vicente (parte do anel rodoviario) ou a alca do BH Shopping-Nova Lima.... O bairro aqui fez uma mobilizacao para ganhar porque so quem mora aqui sabe o que passamos, dito e feito, vencemos o OP que naquele ano era 1 obra por ano.... a Pca Continua a mesma, a prefeitura diz que nosso 
OP ficou pendente por causa da reestruturacao do anel rodoviario.... ou seja, estamos esperando o anel ser reformado! (NUNCA) ja no Belvedere, a alca saiu a muito tempo.... Essas obras so visa melhorar interesses publicos e politicos! (Postagem n. 129, OPD 2011)

Mesmo com o grande descrédito deflagrado, foram identificadas manifestações sobre controle social, sobre mobilização popular, que estão vinculadas a uma lógica de coletividade:

O dia que pensarmos mais em priorizar o interesse COLETIVO ao invés do interesse próprio, o mundo mudará. Saneamento básico é um direito de todos e não pra pensar no lazer de um campo de futebol sem antes lembrar das pessoas que convivem com esgoto a céu aberto e sem asfalto na Basílio da Gama. Não moro próximo a nenhuma das duas obras e poderia optar pelas câmeras de monitoramento... mas prefiro votar na DIGNIDADE HUMANA que trará a obra da Av. Basílio da Gama. (Postagem n. 785, OPD 2011)

Um ponto interessante, que merece destaque, foi a mobilização em torno de uma das obras (av. Basílio da Gama), que reverteu um placar negativo e conseguiu se sagrar vencedora em sua região. A grande mobilização das pessoas, utilizando basicamente recursos das TIC, foi determinante para a vitória da obra.

\section{Conclusão}

Criado, em 2006, pela Prefeitura de Belo Horizonte, o OP Digital tinha como objetivo ampliar a participação das pessoas no processo deliberativo local e, ainda, incluir novos públicos que historicamente têm baixa participação no OP presencial: os jovens e a classe média. As TIC possuem potencial latente para integrar pessoas e mesmo ser empregadas como canal de debate e troca de ideias, dadas suas características de comunicação de um para muitos e de muitos para muitos. Por conta disso, elas foram o repositório de esperanças para a concretização de uma nova democracia, uma cyber-democracia ou e-democracia. Entusiastas vislumbram as TIC fortalecendo o éthos democrático em nossa sociedade.

Ao analisarmos a experiência do OP Digital da cidade de Belo Horizonte, podemos constatar que, na primeira edição do OPD, em 2006, o grande sentido expresso pelos cidadãos foi de expectativa democrática. Nota-se um sentimento de esperança e consolidação de diversos anseios democráticos. E isso pode ser notado em falas como "Quem convive com movimentos sociais como o da ASMARE percebe na pele que esta nova cultura, redentora, está sim nascendo, surgindo e se sedimentando" (Postagem n. 104, OPD 2006), que ficaram demonstradas na rede de códigos obtida através do Atlas TI 6.0®.

Em 2008 esse sentido é convertido em algo que se aproxima de uma ideia de competição, de cunho mais individualista, que ganha, inclusive, uma conotação de disputa de "classes" nos discursos dos cidadãos. Discursos do tipo “(...) POIS OS RICOS DA ZONA SUL, PODEM ATE COMPRAR HELICOPTEROS PARA SE LOCOMOVER NA CAPITAL (...)” (Posta- 
gem n. 563, OPD 2008) retratam tal cenário. O que importa nesse caso é aqui o que é melhor para cada um. Ainda que oficialmente a intenção da $\mathrm{PBH}$ fosse debater a pólis e fomentar um sentimento de integração (Prefeitura de Belo Horizonte, 2008), o que se percebeu foi uma grande competição entre os cidadãos, dividindo, em alguns momentos de debate, a cidade entre "ricos e pobres".

Na última edição, o que se percebe é uma forte desilusão com esta modalidade de participação. Postagens como "ESTA OP DIGITAL E SO PARA ENGANAR O ELITOR/CONTRIBUINTE, NAO FAZEM NADA DO QUE GANHAM E AINDA TEMOS QUE OUVIR QUE UM DIA VAI FAZER" (Postagem n. 467, OPD 2011) demonstram tal sentimento, que teve um reflexo direto no ânimo participativo da população.

Cabe retomar o objetivo do presente artigo: deslindar os sentidos e significados da participação democrática mediada pela Internet, dentro da experiência do OPD de Belo Horizonte, a partir da visão dos cidadãos.

Buscando atingir o objetivo proposto, pode-se concluir que o significado que a democracia assume em cada edição mantém os tons dos sentidos atribuídos ao contexto democrático em cada discurso. Inicialmente, pode-se inferir, a partir dos discursos analisados, que o significado democrático da experiência se aproxima de um modelo de democracia participativa. Em seguida, podemos tipificar o significado da democracia na edição de 2008, como "competitiva". ${ }^{2}$ E, na última edição, o significado pode ser lido como uma dinâmica de crise de legitimidade democrática.

Os sentidos e significados da participação democrática através da Internet são modificados ao longo das três edições. É cabível uma nova pesquisa para aprofundamento e certificação dessas causas, mas fica evidenciado pelas análises das falas dos cidadãos que a relação entre o Estado (governo) e a sociedade, no sentido de cumprir o que fora acordado, é determinante para moldar os sentidos e significados vivenciados pelos cidadãos.

Esta investigação traz à tona interessantes pistas para reflexão sobre o uso das TIC nos processos democráticos. Até que ponto as dimensões do coletivismo e do individualismo pesam em estratégias de participação digital? Qual a influência de aspectos materiais (posição social etc.) em processos de e-democracia? Quais as possibilidades de integração entre a participação digital e a "analógica"? Ainda não se sabe também muito sobre o comportamento do cidadão no meio presencial e digital, que diferenças comportam. Os OPD são arenas de construção coletiva pelo meio digital, não há dúvida, mas não se sabe ainda se seriam mais democráticos do que as experiências presenciais. Esses são possíveis problemas para pesquisas futuras nessa temática. Este trabalho possui, como principal limitação, o fato de não ter realizado nenhuma entrevista em profundidade com cidadãos que vivenciaram a experiência do OPD.

\footnotetext{
${ }^{2}$ Não me refiro aqui ao modelo de democracia competitiva schumpeteriano, mas sim algo presente entre os cidadãos, e não no método democrático, diferente do que assevera Schumpeter: "o método democrático é um sistema institucional, para a tomada de decisões políticas, no qual o indivíduo adquire o poder de decidir mediante uma luta competitiva pelos votos do eleitor" (Schumpeter, 1961:321).
} 


\section{Referências}

AIKENS, Geoffrey. A democracia eletrônica. Cadernos Escola Legislativa, Belo Horizonte, v. 5, n. 8, p. 41-101, jul./dez. 1998.

AINSWORTH, Susan; HARDY, Cynthia; HARLEY, Bill. Online consultation: E-democracy and Eresistance in the case of the development gateway. Management Communication Quarterly, v. 19, n. 1, p. 120-145, 2005.

AKUTSU, Luiz; PINHO, José Antonio G. Governo, accountability e sociedade da informação no Brasil: uma investigação preliminar. In: Anais do ENANPAD: Encontro da Associação de Pós-graduação em Administração. Campinas, 2001. CD.

AL-KODMANY, Kheir. Public participation: technology and democracy. Journal of Architectural Education, v. 53, n. 4, p. 220-228, 2000.

AVRITZER, Leonardo. A relevância política da participação popular. Le Monde Diplomatique Brasil, mar. 2009. Disponível em: <http://diplomatique.org.br/artigo.php?id=482>. Acesso em: $1^{\circ}$ mar. 2010.

AVRITZER, Leonardo; NAVARRO, Zander (Org.). A inovação democrática: o Orçamento Participativo no Brasil. São Paulo: Cortez, 2003.

BARBOSA, Alexandre. Governo eletrônico: dimensões da avaliação de desempenho na perspectiva do cidadão. Tese (doutorado em administração) — Escola de Administração de Empresas de São Paulo, São Paulo, 2008.

BERMAN, Jerry; WITZNER, Daniel. Technology and democracy. Social Research, v. 64, n. 3, p. 1313-1319, 1997.

BEST, Nina Juliette et al. Internet e a participação cidadã nas experiências de orçamento participativo digital no Brasil. Cadernos PPG-AU/FAUFBA, v. 9, n. edição especial, p. 105-124, 2010.

BEYNON-DAVIES, Paul et al. The electronic procurement of ideas. International Journal of Electronic Business, v. 2, n. 1, p. 3-19, 2004.

BINGHAM, Lisa B. et al. The new governance: practices and processes for stakeholder and citizen participation in the work of government. Public Administration Review, v. 65, n. 5, p. 547-558, 2005.

CANÇÃO, Rosario. Análise qualititavia de dados com o NVIVO. Departamento de Engenharia de Informática da Universidade de Coimbra, Portugal, 2006. Disponível em: <www.slideshare.net/ rosariocacao/anlise-qualitativa-de-dados-com-o-nvivo-1334976>. Acesso em: 10 mar. 2011.

CHADWICK, Andrew; MAY, Christopher. Interaction between states and citizens in the age of the Internet: "E-government" in the United States, Britain, and the European Union. Governance - An International Journal Of Policy And Administration, v. 16, n. 2, p. 271-300, 2003.

CUNHA, Eleonora; ALLEGRETTI, Giovanni; MATIAS, Marisa. As tecnologias de informação e comunicação na gramática dos Orçamentos Participativos: tensões e desafios de uma abordagem 
essencialmente subordinada. In: CONGRESSO COMUNICAÇÃO E POLÍTICA, 2007, Belo Horizonte. Anais Compolítica. Disponível em: <www.fafich.ufmg.br/compolitica/anais2007/gt_cd-eleonora. pdf>. Acesso em: $1^{\circ}$ fev. 2011.

CUNHA, Maria Alexandra; POZZEBON, Marlei. O uso das tecnologias da informação e comunicação para melhoria da participação na tomada de decisão pública. In: ENCONTRO DA ASSOCIAÇÃO DE PÓS-GRADUAÇÃO EM ADMINISTRAÇÃO, 2009, São Paulo. Anais XXXIII EnANAPD. São Paulo, 2009. CD.

DELUCA, Kevin Michel; PEEPLES, Jennifer. From public sphere to public screen: democracy, activism, and the "violence" of Seattle. Critical Studies in Media Communication, v. 19, n. 2, p. 125-151, 2002.

DUTRA, Olivio; BENEVIDES, Maria Victoria. Orçamento Participativo e socialismo. São Paulo: Perseu Abramo, 2001.

DUTTA-BERGMAN, Mohan. Access to the Internet in the context of community participation and community satisfaction. New Media and Society, v. 7, n. 1, p. 89-109, 2005.

ELWOOD, Sarah. GIS and collaborative urban governance: understanding their implications for community action and power. Urban Geography, v. 22, n. 8, p. 737-759, 2001.

FARIA, Antonio; PRADO, Otavio. Orçamento Participativo Interativo. 20 experiências de gestão pública e cidadania. São Paulo: FGV-SP, 2003.

FEDOZZI, Luciano. Observando o Orçamento Participativo de Porto Alegre - análise histórica de dados: perfil social e associativo, avaliação e expectativas. Porto Alegre: Tomo Editorial, 2007.

FEDOZZI, Luciano. Teorias democráticas, participação e transformação social. In: SEMINÁRIO INTERNACIONAL SAÚDE E DEMOCRACIA: PARTICIPAÇÃO POLÍTICA E INSTITUCIONALIDADE DEMOCRÁTICA, CEBES, 26-27 jun. 2008, Rio de Janeiro. Mimeografado.

GIMMLER, Antje. Deliberative democracy, the public sphere and the internet. Philosophy \& Social Criticism, Londres, v. 27, n. 4, p. 21-39, 2001.

GONÇALVES, Hermes L. Uma visão crítica do Orçamento Participativo. Rio de Janeiro: Lumen Juris, 2005.

HACKER, Kennet. The potential of computer-mediated communication (CMC) for political structuration. Javnost-The Public, v. 11, n. 1, p. 5-25, 2004.

HELD, David. Models of democracy. 3. ed. Palo Alto, CA: Stanford University Press; Polity Press, 2006.

HUDSON-SMITH, Andrew; EVANS, Stephen; BATTY, Michael. Building the virtual city: public participation through edemocracy. Knowledge, Technology and Policy, v. 18, n. 1, p. 62-85, 2005.

JAMBEIRO, Oton et al. Cidades digitais, telefonia móvel e interação social na sociedade brasileira. Razón y Palabra, México, v. 49, n. Especial, 2006.

KENSKI, Kate. To I-Vote or not to I-Vote?: opinions about Internet voting from Arizona voters. Social Science Computer Review, v. 23, n. 3, p. 293-303, 2005. 
KNIGHT, Peter et al. e-gov.br: a próxima revolução brasileira. Rio de Janeiro: Prentice-Hall, 2004. LOURENÇO, Rui Pedro; COSTA, João Paulo. Discursive e-Democracy support. In: Proceedings of the 39th Annual Hawaii International Conference on System Sciences. Havaí: Computer Society Press, 2006. CD.

LUHRS, ROLF et al. How to grow? Online consultation about growth in the City of Hamburg: methods, techniques, success factors. In: TRAUNMÜLLER, Roland (Ed.). EGOV 2003. Berlim: Springer-Verlag, 2003. p. 79-84.

MILES, Matthew; HUBERMAN, Michel. Qualitative data analysis. Thousand Oaks: Sage Publications Inc., 1994.

MORENO-JIMENEZ, José Maria; POLASEK, Wolfgang. e-Cognocracy and the participation of immigrants in e-governance. Viena: Department of Economics and Finance, Institute for Advanced Studies, 2005. v. 169. (Economics series).

NOGUEIRA, Marco Aurélio. Organizações complexas e sociedade da informação. O "sofrimento" como metáfora organizacional. Organizações e Sociedade, v. 10, n. 28, p. 145-162, set./dez. 2003.

PEIXOTO, Tiago. Beyond Theory: e-Participatory budgeting and its promises for eParticipation. European Journal of Practice, n. 7, p. 55-63, mar. 2009.

PINHO, José Antonio G. Sociedade da informação, capitalismo e sociedade civil: reflexões sobre a política, Internet e democracia na realidade brasileira. Revista de Administração de Empresas, São Paulo, v. 51, n. 1, p. 98-106, jan./fev. 2011.

PINHO, José Antonio G.; WINKLER, Ingrid. Política presencial versus política virtual: uma investigação no Fórum Digital de Debates entre Docentes na Universidade Federal. In: INTERNATIONAL MEETING OF THE IBEROAMERICAN ACADEMY OF MANAGEMENT, 6TH, 2009, Buenos Aires. Anais do 6th International Meeting of the Iberoamerican Academy of Management, CD, Buenos Aires, 17p. 2009.

PREFEITURA DE BELO HORIZONTE. Relatório da Secretaria Municipal Adjunta de Planejamento. Belo Horizonte, CD, 2008.

SAMPAIO, Rafael C.; BARROS, Chilani T. G. Internet como esfera pública? Análise de usos e repercussões reais das discussões virtuais. Estudos em Comunicação/Communication Studies, n. 9, p. 161-183, 2011.

SANCHEZ, Felix. Orçamento Participativo: teoria e prática. São Paulo: Cortez, 2002.

SANFORD, Jeremy; ROSE, Clive. Characterizing eParticipation. International Journal of Information Management, v. 27, n. 6, p. 406-442, 2007.

SANTOS, Boaventura S. Democratizar a democracia: os caminhos da democracia participativa. Rio de Janeiro: Civilização Brasileira, 2002 (Reinventar a Emancipação Social: para novos manifestos).

SANTOS, Ernani M. Desenvolvimento e implementação de padrões de interoperabilidade em governo eletrônico no Brasil. Tese (doutorado em administração) — Universidade de São Paulo, São Paulo, 2008a. 
SANTOS, Ernani M.; REINHARD, Nicolau. Padrões de interoperabilidade para governo eletrônico no Brasil: um estudo de caso do desenvolvimento e implementação da arquitetura e-PING sob a ótica institucional. In: ENCONTRO DE ADMINISTRAÇÃO PÚBLICA/ANPAD, 2008, Salvador. Anais... Salvador: EnAPG/ANPAD, 2008b

SCHUMPETER, J. A. Capitalismo, socialismo e democracia. Rio de Janeiro: Fundo de Cultura, 1961.

SERAFIM, Lizandra. Controle social nas agências reguladoras brasileiras: entre projetos políticos e modelo institucional. CSOnline - Revista Eletrônica de Ciências Sociais, v. 2, n. 5, p. 202-221, dez. 2008.

SVENSSON, Jörgen; LEENES, Ronald. E-voting in Europe: divergent democratic practice. Information Polity, v. 8, n. 1/2, p. 3-15, 2003.

TAYLOR, John; BURT, Eleanor. Voluntary organizations as e-democratic actors: political identity, legitimacy and accountability and the need for new research. Policy and Politics, v. 33, n. 4, p. 601616, 2005.

TRENCH, Brian; O'DONNELL, Susan. The Internet and democratic participation: uses of ICTs by voluntary and community organizations in Ireland. Economic and Social Review, v. 28, n. 3, p. 213234, 1997.

WALTER, Silvana Anita; BACH, Tatiana Marceda. Adeus papel, marca-textos, tesoura e cola: Inovando o processo de análise de conteúdo por meio do Atlas.ti. In: SEMEAD, XII, SEMINÁRIOS DE ADMINISTRAÇÃO, 2009, CD, 17p. São Paulo. Anais, 2009.

WELP, Yanina. Democracia y fractura digital en América Latina. In: CONFERENCIA INTERNACIONAL DEMOCRACIA DIRECTA EN AMÉRICA LATINA, 14-15 mar. 2007, Buenos Aires, Argentina. Disponível em: <www.ddla.ch/download/Welp_Yanina.pdf>. Acesso em: 10 de maio 2011.

ZANELLA, Liane Carly H. Metodologia de estudo e de pesquisa em administração. Florianópolis: Departamento de Ciências da Administração/UFSC; [Brasília]: Capes; UAB, 2009.

Júlio Cesar Andrade de Abreu é administrador, mestre e doutor em administração (Ufba). Professor adjunto II da Universidade Federal Fluminense (UFF), Polo Universitário de Volta Redonda (PUVR), Programa de Pós-graduação em Administração (PPGA/MPA/UFF). E-mail: julioabreu@vm.uff.br.

José Antonio Gomes de Pinho é doutor em planejamento regional pela University of London (LSE), professor associado IV da Universidade Federal da Bahia (Ufba), professor do Núcleo de Pós-Graduação da Escola de Administração da Ufba. E-mail: jagp@ufba.br. 